\section{0 redesenho como instrumento de construção de conhecimento em arquitetura}

Ana Gabriela Godinho Lima, Júlio Luiz Vieira

Ana Gabriela Godinho Lima é doutora em Arquitetura e Urbanismo; professora e pesquisadora na Faculdade de Arquitetura e Urbanismo da Universidade Mackenzie e no PPG-FAUMACK; godinholima.ag@gmail.com

Júlio Luiz Vieira é doutor em Arquitetura e Urbanismo; professor e pesquisador na Faculdade de Arquitetura e Urbanismo da Universidade Mackenzie; julio.vieira@mackenzie.br

\section{Resumo}

Esta comunicação examina o papel do redesenho como instrumento de construção de conhecimento na pesquisa acadêmica em arquitetura. Para tanto estrutura-se em duas partes: a primeira dá conta do suporte teórico construído ao longo do desenvolvimento de projetos de pesquisa em que os autores estiveram engajados, apontando para a formulação e emprego de dois indicadores de avaliação da pesquisa acadêmica em áreas de prática projetual - o indicador histórico/historiográfico e o indicador projetual. A segunda parte detém-se na análise da tese de doutoramento de um dos autores, procedendo à verificação da operação dos indicadores enunciados nas estratégias de investigação adotadas. O foco da argumentação recai sobre o redesenho como estratégia projetual fundamental na construção do conhecimento na pesquisa em arquitetura. Tem ainda em vista que a atividade de redesenhar é sempre situada historicamente.

Palavras-chave: Recursos gráficos. Pesquisa. Historiografia arquitetônica. Pesquisa Acadêmica

\begin{abstract}
This communication examines the redrawing role as instrument of knowledge building in academic research in areas of design practice. It structure is two folded: the first part deals with the theoretical foundation which has been built through research projects with which the authors had took part in. It points out the development and the operation of two indicators in the assessment of academic research in areas of design practice: the historic/historiographical indicator and the design indicator. The second part is dedicated to one of the authors doctoral research analysis. It proceeds to the verification of how the indicators may be operated regarding the investigation strategies adopted. The discussion focus is adjusted on the redrawing as a fundamental strategy in building knowledge in architecture. It also takes into account that the redrawing activity is always historically situated.
\end{abstract}

Keywords: Graphic resources. Research. Architectural Historiography. Academic Research.

\section{Resumen}

Este artículo examina el papel del rediseño como herramienta de construcción de conocimiento en la investigación académica en la arquitectura. Para tanto se estructura en dos partes: la primera presenta una relación de apoyo teórico construído sobre el desarrollo de proyectos de investigación a la que se dedicaban los autores, que apunta a la preparación y la utilización de dos indicadores de evaluación de la investigación académica en las áreas

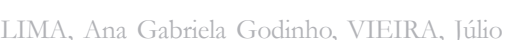


de práctica proyectual - un indicador histórico / historiográfico y outro proyectual. La segunda parte consiste en la análisis de la tesis doctoral de uno de los autores, procediendo a verificar el funcionamiento de los indicadores establecidos en las estrategias de investigación adoptadas. El enfoque del argumento se basa en el rediseño como estrategia proyectual fundamental en la construcción del conocimiento en la investigación de la arquitectura. Además, considera que la actividad de rediseñar se sitúa siempre históricamente.

Palavras-clave: Capacidades graficas. Investigación. La historiografía arquitectónica. La investigación académica.

\section{Introdução}

O objetivo desta comunicação é analisar e descrever, nos termos do rigor da pesquisa acadêmica, características essenciais do papel dos instrumentos de redesenho na pesquisa em projeto de arquitetura.

O marco fundador da análise teórica que aqui empreendemos é constituído pelo relatório do projeto "Pesquisa Acadêmica em Áreas de Prática Projetual: Arquitetura e Urbanismo" - PAAPP, (LIMA et. al. 2011) cujos resultados incluem publicações e desenvolvimento de projetos de pesquisa de Doutorado, Mestrado e Trabalho Final de Graduação. Dentre estes se destacam algumas publicações, como "Proyectos e Métodos proyectuales en La Investigación Académica: Algunos indicadores útiles" (LIMA e ZEIN, 2011), em que se discute a presença constante e a relação entre o que chamamos de indicadores históricos e historiográficos e os indicadores projetuais, na investigação acadêmica em áreas de prática projetual. Com efeito, a constatação de que tais indicadores, um de natureza textual (histórico e historiográfico) e outro de natureza gráfica (projetual), podem ser de grande eficácia no reconhecimento e avaliação da pesquisa acadêmica em áreas projetuais constitui um dos principais resultados do projeto PAAPP.

Evidências da relevância da consideração destes indicadores não apenas como auxiliares no reconhecimento e avaliação da pesquisa que se vale de métodos projetuais (como o redesenho) para a construção de argumentação, mas também como instrumento útil no próprio processo de condução da investigação podem ser encontradas nas publicações, orientações e interlocuções acadêmicas que se seguiram ao projeto. Dentre estas repercussões cabe mencionar ao menos dois artigos. O primeiro, "Proyectos, teorias e investigación: tendencias de la enseñanza en arquitectura y urbanismo." (LIMA et. al. 2011), incorpora alguns elementos da relação entre os modos de produção de conhecimento histórico e projetual na reflexão sobre 
o ensino e a pesquisa em arquitetura e urbanismo no âmbito dos programas de pós-graduação stricto sensu.

Em "Indicadores de Pesquisa Acadêmica em Áreas de Prática Projetual" (LIMA et. al., 2011), os autores foram adiante em relação ao artigo anterior, publicado no mesmo ano por Lima e Zein, propondo alguns desdobramentos do papel do uso dos indicadores, histórico/ historiográfico e projetual no entendimento das estruturas da pesquisa acadêmica em áreas de prática projetual. Diante do exposto, importa descrever, ainda que de modo sucinto, os dois indicadores acima mencionados, históricos e projetual, e os procedimentos adotados para que fossem estabelecidos. Iniciemos pelos procedimentos:

Com base em revisão bibliográfica e discussões entre os membros da equipe do projeto de pesquisa ${ }^{1}$, foram estabelecidas delimitações iniciais dos elementos que compõem o que chamamos de "prática projetual", e de que forma poderiam ser identificados na pesquisa acadêmica;

Como resultado da pesquisa foram construídos argumentos iniciais sobre as características efetivamente encontradas em teses e dissertações de arquitetura e urbanismo que empregam elementos do projeto de arquitetura como parte essencial de sua argumentação. Entretanto, não foi possível propor a existência de diferenças evidentes em relação aos métodos tradicionais de pesquisa. O que se observou foi a associação eficaz entre métodos tradicionais, em especial de natureza histórico/historiográfica, e métodos projetuais. $\mathrm{O}$ que se conseguiu foi estabelecer com clareza dois indicadores que caracterizam as pesquisas que se utilizam de métodos projetuais como parte fundamental de sua argumentação.

\section{Projetual:}

O emprego dos métodos projetuais, tal como empregados no universo de trabalhos analisados, sugere aproximações com a noção de artefato, ou seja, parecem constituir-se em construções não-textuais que têm como objetivo trazer à tona um elemento da problemática envolvida no trabalho que não seria passível de descrição, ou compreensão, por métodos textuais tradicionais.

A construção conceitual deste indicador visa permitir a identificação e legitimação de teses e dissertações que, ao empregarem métodos não-textuais, os aqui chamados artefatos não-textuais, implicam que o pro-
Equipe do projeto "Pesquisa Acadêmica em Áreas de Prática Projetual": Profa. Dra. Ana Gabriela Godinho Lima (líder), Prof. Dr. Rafael Perrone, Profa. Dra. Ruth Verde Zein, Profa. Dra. Cecília Rodrigues dos Santos, Profa. Dra. Maria Isabel Villac, Prof. Ms. Angelo Cecco. Discentes: Agnes del Comune, Maryellen Sanchez, Matheus Vasconcellos, Financiamento: Fundo Mackenzie de Pesquisa - Mackpesquisa. 
cesso de decisões metodológicas e a contextualização e solução do problema podem ser claramente descritos. Ou, poderiam responder ao seguinte questionamento de Scrievener (2000): o pesquisador ou a pesquisadora "demonstrou ter consciência do que estava fazendo e mostrou-se ser capaz de propor e resolver problemas", e adicionamos aqui, por meio do emprego dos artefatos não-textuais?

\section{Histórico / Historiográfico:}

Utilização de métodos históricos ou historiográficos, textuais que contextualizem, justifiquem e situem a preocupação de cunho projetual. O que se observou foi o recurso a métodos históricos/historiográficos como forma de situar com maior precisão o contexto cultural, os tópicos, preocupações e interesses culturais pertinentes aos temas abordados. Esses métodos parecem alinhar-se com os métodos adotados para pesquisas acadêmicas em áreas de arquitetura e urbanismo na Europa e nos EUA. Essa impressão é corroborada pelo trabalho de Borden e Ray, The Dissertation: an architecture student's handbook (2009). Os autores concordam entre si que a pesquisa acadêmica em arquitetura e urbanismo pode assumir características muito variadas e que não há realmente um consenso sobre qual ou quais formas específicas este tipo de pesquisa deveria assumir. Enfatizando os aspectos mais comumente aceitos para a pesquisa acadêmica, como a necessidade de originalidade, assumida pelo/a próprio/a pesquisador/pesquisadora e o reconhecimento das ideias e trabalhos de outros autores quando apropriado. Esse reconhecimento, a nosso ver, passa pelas conexões que a pesquisadora ou pesquisador constrói entre seu trabalho e o saber estabelecido e organizado historicamente.

As conclusões a que o relatório chegou, em 2011, refletiam sobre a relevância do estabelecimento destes indicadores. Para a equipe, esta situava-se principalmente na contribuição para o reconhecimento e legitimação das dissertações de mestrado e teses de doutorado que empregam artefatos não-textuais como meio, método e/ou tema de pesquisa. Nos anos subsequentes, explorações destes resultados tomaram lugar.

Dentre estas, cabe comentar sucintamente o projeto intitulado "Práticas Projetuais: práticas de projeto de arquitetas, arquitetos e designers: análise dos instru-

2 Financiamento Fundo Mackenzie de Pesquisa: Mackpesquisa. mentos de prática projetual e possíveis empregos, de forma direta ou não - na pesquisa acadêmica stricto sensu" $(2012 / 2014)^{2}$. Dedicou-se à investigação das 
práticas projetuais em arquitetura, urbanismo e design, buscando identificar e descrever os modos pelos quais estas podem ser empregadas como forma de construção do conhecimento acadêmico. Instrumentos projetuais incluindo croquis, estudos preliminares, construção de modelos físicos e virtuais, elaboração de plantas, cortes e elevações - em versões de estudo e versões representadas tecnicamente - além de estudos fotográficos e de natureza visual, compõem a prática habitual do projeto de arquitetura e urbanismo. Entretanto, quando utilizados como procedimento para a construção do conhecimento acadêmico em teses de doutorado, dissertações de mestrado e até mesmo pesquisas de Iniciação Científica, enfrentam alguns aspectos problemáticos.

O principal problema abordado consistiu na identificação e descrição das relações entre as práticas profissionais em projeto de arquitetura e urbanismo e as concepções e implicações envolvidas quando o pesquisador engaja-se na pesquisa acadêmica, notadamente teses de doutorado, dissertações de mestrado e iniciações científicas, em projeto de arquitetura e urbanismo. O projeto pretendeu formular enunciados que contribuíssem para a literatura de auxílio a orientadores, membros de bancas examinadoras e membros de órgãos de fomento à pesquisa. Orientadores, por exemplo, podem achar útil contar com enunciados claros e que contemplem o contexto brasileiro, sobre tópicos como: 1. modos de abordagem à literatura convencional versus outras fontes mais específicas ao projeto; 2. Estratégias de construção da argumentação; 3. Metodologias válidas de pesquisa utilizando métodos projetuais; 4. Demonstração e comunicação clara.

As conclusões iniciais indicam por um lado, que as práticas habituais do fazer e pensar da vida profissional são profundamente desafiadas ao longo do processo de construção da dissertação ou tese, em espacial no que se refere à elaboração do texto acadêmico. Por outro, aspectos como intuição sobre o caminho correto a seguir, estratégias para organização do trabalho e, principalmente, os recursos visuais, como o emprego de fotografias, mapas, reprodução de desenhos e o redesenho constituíram-se no elemento essencial na construção da argumentação e desenvolvimento do trabalho.

A nosso ver, esses resultados corroboraram a validade dos dois indicadores acima mencionados: histórico/ historiográfico e projetual. No que tange ao indicador histórico, verificamos sua relevância no exame dos 
seguintes aspectos das pesquisas encaminhadas pelos profissionais entrevistados:

- delimitação do recorte da pesquisa;

- seleção de bibliografia a ser revisada;

- estabelecimento do referencial teórico;

- desenvolvimento das analyses.

Cada um destes aspectos é orientado por elementos de raiz histórico/historiográfica. Cabe notar, entretanto, que os pesquisadores e pesquisadoras elaboram seleções bibliográficas e referenciais teóricos de modo mais guiado pelos autores e publicações valorizados ao longo do ensino de graduação e aulas da pós-graduação e em conversas com os orientadores e orientadoras, do que por uma construção metodológica, embasada nas vertentes historiográficas correntes. Em outras palavras, muitas vezes o pesquisador ou pesquisadora pode utilizar, em uma mesma análise, autores de diferentes correntes de pensamento, sem sentir a necessidade de explicitar, em seu argumento, o porquê da articulação de argumentos provenientes de autores que são considerados, muitas vezes, bastante antagônicos ou cujas perspectivas parecem incompatíveis.

No contexto desta comunicação não cabe discutir a validade ou não de operações metodológicas dessa natureza, mas apenas apontar para o fato de que talvez seja desejável fortalecer o debate no sentido de se discutir a conveniência de se tornarem mais explícitas as abordagens historiográficas efetivamente empregadas na pesquisa acadêmica em áreas de prática projetual.

O emprego do indicador projetual nos permite focalizar as estratégias de trabalho cuja fundamentação principal é a experiência adquirida ao longo da prática profissional. Acerca deste indicador é interessante notar o que nos parecem ser áreas de sobreposição com relação ao indicador histórico/historiográfico. Isto ocorre em particular na seleção de obras e autores, que, para praticantes experientes, tende a ser uma opção guiada pelas leituras ocorridas nos períodos de formação, leituras de atualização profissional e também uma identificação de edifícios e profissionais que contam com reconhecimento entre os pares no meio profissional.

De qualquer modo, os principais aspectos avaliados por esse indicador são aqueles ligados à elaboração 
de modelos físicos, mapas, plantas, cortes, fachadas, elevações, esquemas, croquis. Também a seleção e organização de fotografias nas páginas que compõem o trabalho são realizadas com base na experiência adquirida ao longo dos anos de prática profissional. Nesse conjunto, o redesenho é adotado como estratégia privilegiada na construção e explicitação dos entendimentos decorrentes das análises empreendidas no contexto da pesquisa.

O trabalho que aqui elegemos para análise ilustra aspectos específicos do emprego do redesenho como ferramenta construída com base na prática projetual do autor, como veremos mais adiante. Por ora, nos detemos em algumas considerações que nos parecem oportunas acerca do modo como os indicadores podem ser manejados na análise de trabalhos acadêmicos.

\section{Identificação e verificação dos indicadores histórico/historiográfico e projetual na pesquisa acadêmica}

Uma vez enunciados e descritos os indicadores acima, a pergunta é: como efetivamente identificar, descrever e analisar seu emprego na pesquisa acadêmica que emprega instrumentos da prática projetual, como o redesenho, como parte essencial na construção da argumentação?

Em primeiro lugar, como já dissemos, é necessário ter em vista de que toda construção intelectual, textual e não-textual, está situada dentro de um campo disciplinar construído historicamente, e é neste contexto que empregamos o indicador histórico/historiográfico em primeiro lugar, no intuito de verificar o posicionamento histórico, explicitado ou não, do pesquisador.

\section{Verificação do indicador histórico/historiográfico}

A história, a historiografia e a bibliografia da arquitetura têm, nesse contexto, um papel importante ao conferir sentido à produção arquitetônica, organizando arquiteturas, projetistas e lugares em escalas de valores específicas. Sendo ensinada parte sob a forma de texto, parte sob a forma de imagens, a história da arquitetura tem um efeito importante na criação do sentido de realidade que as e os estudantes constroem mentalmente. Como pondera Marina Waisman (2009), enquanto os problemas históricos se referem à existência do fato histórico - sua verossimilhança, a data, a autora ou autor, as circunstâncias de sua pro- 
dução - os problemas historiográficos comprometem diretamente a ideologia do historiador, implicada na seleção do objeto de estudo, de seus instrumentos críticos, da estrutura do texto e "tudo aquilo que conduzirá à interpretação do significado dos fatos e, em definitivo, à formulação de sua versão do tema escoIhido" (Waisman: 2009, pg. 15).

Com isso em vista, o exame do indicador histórico/ historiográfico exige, por parte do examinador, algum conhecimento prévio sobre as principais correntes historiográficas empregadas na pesquisa acadêmica em arquitetura e urbanismo. Borden e Ray (2009) compilam, em âmbito internacional, as vertentes historiográficas mais comumente empregadas nesse campo de pesquisa: empirismo; iconografia; história e teoria hegeliana; história social; história e teoria política; história e teoria operativas; estudos teóricos e interdisciplinares; ciências sociais; escrita pessoal; estudos fundamentados em análises visuais.

\section{Verificação do indicador projetual}

A verificação do indicador projetual em pesquisas acadêmicas fundamentadas na prática projetual convocaria um examinador que possuísse, necessariamente, experiência na prática de projeto? Este é certamente um ponto que merece reflexão e debate cuidadosos. O que se pode dizer, por certo, é que é necessário que o examinador esteja a par do debate sobre a pesquisa nesse âmbito e suas características essenciais. Como nos lembra Doris Kowaltowsky, em sua apresentação à edição brasileira do livro de Bryan Lawson, "Como Arquitetos e Designers pensam" (2011), foi o pesquisador inglês Nigel Cross, um dos fundadores do periódico Design Studies que identificou os principais assuntos discutidos acerca dos métodos de projeto:

1. o controle do processo de projeto;

2. a estrutura dos problemas de projeto;

3. a natureza da atividade de projeto;

4. a filosofia do método de projeto.

A aferição do indicador projetual poderia passar, a critério do examinador, por um primeiro estágio em que se verifica se, de fato, o trabalho em questão caracteriza-se como pesquisa fundamentada na prática projetual. Isso implicaria na presença de dois elementos:

1. a construção da argumentação central do trabalho envolve necessariamente o emprego de instrumentos projetuais, ou seja, não prescinde do desenho e de elementos gráficos para sua construção e demonstração e 
2. enquadra-se em um contexto mais amplo do debate acadêmico, como as quatro vertentes enumeradas acima ou, possivelmente, outras que estejam em atuação. Isso garantiria que se trata de pesquisa em nível acadêmico, e não de natureza técnica, cujas finalidades são, como se sabe, muito diferentes.

Uma vez constatada a adequação da pesquisa às temáticas ligadas à prática projetual, a verificação passaria então a examinar a construção e demonstração dos argumentos, com ênfase no processo, mas não perdendo de vista os resultados alcançados no final.

Do ponto de vista do processo, importa analisar a presença dos elementos não-textuais sob pelo menos três ângulos: o enunciado do objetivo que indica a necessidade do uso de elementos gráficos para que seja atingido; o modo como os recursos gráficos foram construídos para atingir o objetivo; a habilidade demonstrada na apresentação dos elementos gráficos elaborados deste modo. Do ponto de vista do produto final, a resposta a três questões essenciais pode contribuir para um exame mais acurado (LIMA et al. 2011):

O trabalho apresenta claramente a caracterização do problema e o uso de elementos gráficos é a solução mais apropriada para respondê-lo?

É possível demonstrar ou constatar claramente que o uso dos elementos gráficos foram a solução mais apropriada para resolver o problema;

A utilização da solução adotada pode ser comunicada coletivamente e beneficiar outros pesquisadores que se deparem com problemas semelhantes?

Em síntese, os tópicos que compõem esse indicador visam contribuir para a identificação, reconhecimento e valorização da pesquisa acadêmica que, ao utilizar métodos gráficos, como o redesenho, constrói um tipo de conhecimento que não poderia ser atingido por outra via. No presente trabalho, buscamos refletir especificamente sobre como a prática do redesenho constitui-se em ferramenta essencial para o desenvolvimento da construção dos conhecimentos históricos e historiográficos em arquitetura. De modo a substanciar a primeira parte deste trabalho, em que propomos a definição de dois indicadores de análise para a pesquisa acadêmica em áreas de prática projetual, na segunda parte, discutimos uma pesquisa específica, uma tese de doutorado, em que os elementos discutidos na primeira parte comparecem como estratégia de execução do 
trabalho e recurso para a reflexão a posteriori sobre os resultados alcançados ao seu final.

\section{Reconstrução de um percurso de pesquisa: vias de aproximação para uma leitura da condição espacial na arquitetura}

\section{A construção de uma abordagem pelo redesenho}

No âmbito da crítica arquitetônica ou da pesquisa historiográfica, o redesenho de obras de arquitetura, construídas ou não, representa um recurso cujo poder elucidatório sobre as qualidades espaciais de uma obra não pode ser substituído por formas textuais de descrição. Esse é um dos pressupostos da tese "Vias de Aproximação para uma Leitura da Condição Espacial na Arquitetura" (2015), que buscou traçar uma estratégia de abordagem da "leitura" das qualidades espaciais de obras arquitetônicas, fazendo uso de elementos gráficos obtidos a partir da interação com a documentação gráfica sobre uma seleção de obras.

As qualidades espaciais com poder de determinar experiências vitais do homem em seu ambiente, tomadas em conjunto, caracterizarão uma condição particular, uma natureza, uma índole dos espaços para a arquitetura. Algo que possibilite defini-la como um organismo espacial com uma marca identitária; que ao mesmo tempo ajude a singularizá-la como fenômeno, mas que também auxilie na identificação de sua linhagem histórica.

A ação de redesenho das obras, com o propósito específico de utilização como instrumento de visualização desta "condição espacial", como mencionado acima, requereu alguns instrumentos específicos. Foi necessário intervir sobre os desenhos "originais" no sentido de produzirem-se "filtros" condizentes com as informações que se desejavam flagrar e que associavam-se com os conceitos espaciais elencados para as leituras.

Vale salientar que a intervenção nos desenhos originais foi o que permitiu a explicitação de certos "valores espaciais" recônditos, constituindo-se em artifício basilar para os confrontamentos que se sucederam. Não obstante a circunstância de que o estudo teve como eixo a ponderação sobre edifícios urbanos públicos ou semipúblicos, observa-se que o método utilizado aplica-se igualmente a outros tipos de edifício, em que pese o fato de que ajustes em relação ao conjunto de conceitos observáveis podem vir a ser necessários. 
No caso especifico da tese em questão, o que se objetivou com cada leitura foi captar aspectos da espacialidade arquitetônica que permitissem a identificação de sua natureza particular. Cada conceito utilizado correspondeu a um aspecto espacial que se buscou entender.

O indicador histórico / historiográfico é representado pela escolha da literatura que deu suporte à construção da estrutura temática conceitual para as leituras, que foi constituída em função da objetividade das abordagens empregadas, avaliadas como detentoras de um grau significativo de operatividade.

Nesse conjunto destacam-se os trabalhos de Herman Hertzberger (2006 e 2010), Bernard Leupen (1999) e Simon Unwin (2003), quem tem em comum o fato de seus autores serem arquitetos contemporâneos dedicados ao estudo analítico da arquitetura, que se utilizam de métodos que envolvem o uso de iconografias das obras e redesenhos dos projetos com o intuito de enfatizar aspectos específicos do estudo do espaço. Do mesmo modo, tais autores apresentam afinidades ideológicas, no sentido de incorporarem em suas análises, visões revisionistas em relação ao ideário moderno característico dos primeiros anos do século $X X$. Notadamente, esses autores incorporam em suas análises discussões que apenas se tornaram comuns para o campo da crítica arquitetônica nos anos 1950, como a consideração do contexto físico circundante na determinação das premissas ao projeto arquitetônico, o conceito de "lugar", ou espaço existencial, no entendimento e resgate das qualidades urbanas da cidade tradicional para o pensamento do espaço urbano contemporâneo.

Os indicadores projetuais estão representados pela reunião dos conceitos que fundamentam as principais reflexões contidas no trabalho. A eleição dos conceitos para constituição da estrutura temática para as leituras se deu, preliminarmente, como uma reflexão sistemática ensejada pela experiência de anos na prática e no ensino do projeto arquitetônico, tendo sido pautada por uma visão de raiz humanista, na tradição desenvolvida por Ernesto Nathan Rogers (apud Montaner, 2002), para quem a arquitetura deveria ser a grande peça integradora nas ações de reparação do espaço urbano, que deveria partir necessariamente das condições da realidade existente, superando os modelos uniformizadores do estilo internacional. Uma abordagem existencialista do espaço urbano está contida também no trabalho de Christian Norberg-Schulz (1975) com a definição do genius loci (ou espírito do 
3 As versões em língua inglesa utilizadas originalmente para o termo "via" dividem-se entre os termos "routes" e "ways". Na versão original da tese em análise, o termo "ways" foi empregado na versão em inglês do resumo e do próprio título, como pode ser constatado no cadastro do banco de dados da Biblioteca de teses e dissertações da Universidade de São Paulo. lugar) para construir um conceito de espaço existencial, ou simplesmente 'lugar', que se desenvolve usando os instrumentos da fenomenologia e da obra filosófica de Martin Heidegger.

A partir daí enumeraram-se sete elementos essenciais de análise: contexto; ocupação; permeabilidade; sociabilidade; fluxos; estratificação e estrutura. Para esta estrutura temática adotou-se, no trabalho, a denominação de "vias de aproximação", sugerindo a ideia de "caminho", "meio".

\section{Sete vias de aproximação: estratégias de redesenho ${ }^{3}$}

Para esta estrutura temática assumiu-se no trabalho a denominação de "vias de aproximação", sugerindo a ideia de "caminho", "meio". A organização sequencial das "vias de aproximação" responde a um critério que reproduz um percurso que se traça do geral ao específico, da maior para a menor escala, o que justifica iniciar-se pelo item que trata das relações da arquitetura com seu contexto físico e, gradativamente, direcionar-se ao interior dos objetos. De certo modo, busca também reproduzir os passos do processo de projeto de arquitetura, identificando-se com o processo de tomadas de decisão.

\section{Primeira via: contexto}

A via correspondente ao "contexto", tem como estratégia o confrontamento das geometrias do perímetro do conjunto edificado (em planta e elevação) com as geometrias planificadas das massas edificadas que compõem o entorno imediato.

No primeiro diagrama (Figura 01), a planta de situação com foto aérea ao fundo destaca o perfil da projeção da massa edificada sobre o terreno, assim como os limites do lote de implantação e a marcação das linhas de referência traçadas junto (paralelas) ao perfil da projeção da massa edificada sobre o terreno. O segundo diagrama (Figura 02) apresenta os mesmos elementos gráficos, porém sem o fundo fotográfico, para melhor visualização das geometrias que compõem a forma projetada. Os perfis das massas edificadas são confrontados com o perfil dos edifícios circundantes também em altura por meio de uma elevação urbana esquemática (Figura 03).

O conjunto dos diagramas visa a leitura da condição es- 

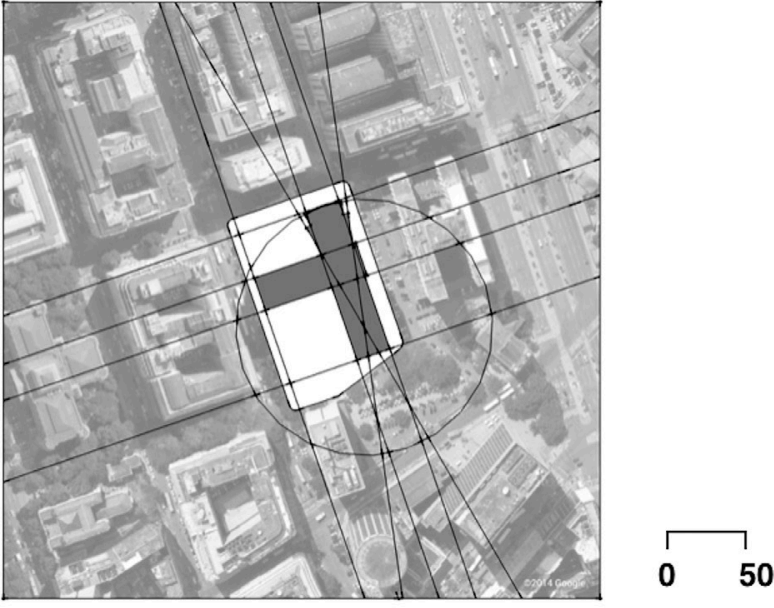

Figura 01

Ministério da Educação e Saúde do Rio de Janeiro. Lucio Costa, Oscar Niemeyer e equipe.

Planta de situação com foto aérea ao fundo. Fonte: Vieira, 2015, p. 151 (publicação autorizada pelo autor).

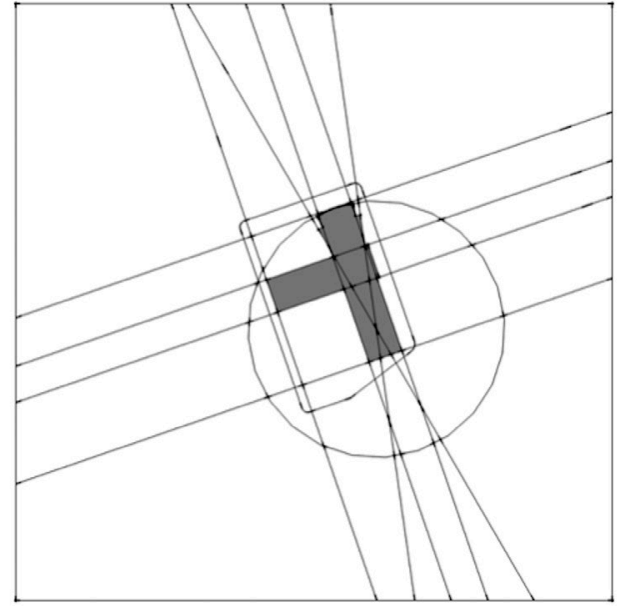

\section{Figura 02}

Ministério da Educação e Saúde do Rio de Janeiro. Lucio Costa, Oscar Niemeyer e equipe. Planta de situação.

Fonte: Vieira, 2015, p. 151 (publicação autorizada pelo autor).

pacial determinada pela relação geométrica entre o contexto e o conjunto edificado. Essa relação pode se estabelecer por ideias visuais que expressem integração; articulação; repetição; ajuste; continuidade e ruptura.

\section{Segunda via: ocupação}

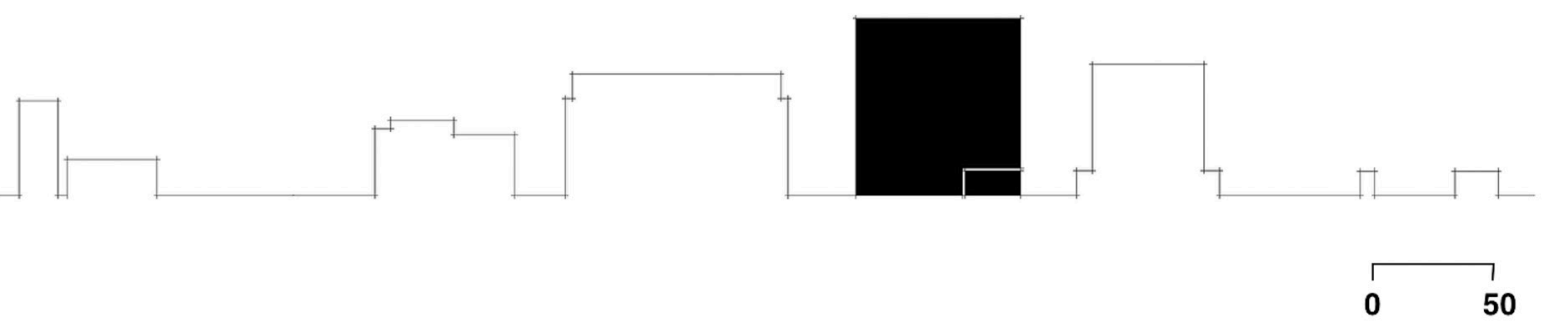

Figura 03

Ministério da Educação e Saúde do Rio de Janeiro. Lucio Costa, Oscar Niemeyer e equipe. Elevação urbana esquemática feita com base nos dados adquiridos do Google Earth.

Fonte: Vieira, 2015, p. 152 (publicação autorizada pelo autor).

Para possibilitar a leitura da condição espacial determinada pela morfologia da projeção do conjunto edificado sobre a área de intervenção, desenvolveu-se um conjunto de peças gráficas destinado a compreender as relações ambivalentes entre geometria da ocupação e do espaço livre, entre massa e vazio. 
No diagrama de figura e fundo da implantação (Figura 04), a cor escura (figura) representa a projeção do conjunto edificado e as linhas espessas, as barreiras representadas pelos muros laterais e empenas vizinhas. Na Figura 05, a síntese gráfica da implantação incorpora as linhas normais externas às fachadas tomadas em cada segmento de inflexão direcional. 0 encontro de duas ou mais linhas normais indicarão uma configuração de envolvência formal.

A ideia subjacente à verificação da envolvência das formas edificadas em relação aos vazios, é a de que perímetros envolventes têm mais capacidade de gerar recintos externos.

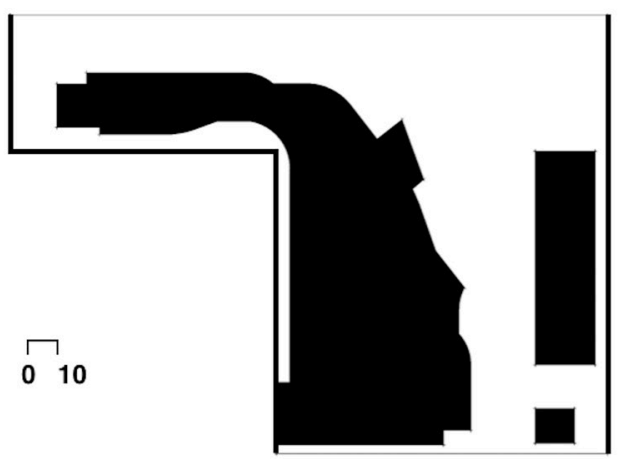

Figura 04

Museu de Arte Nacional do século XX, Roma. Zaha Hadid.

Figura-fundo da implantação.

Fonte: Vieira, 2015, p. 182 (publicação autorizada pelo autor).

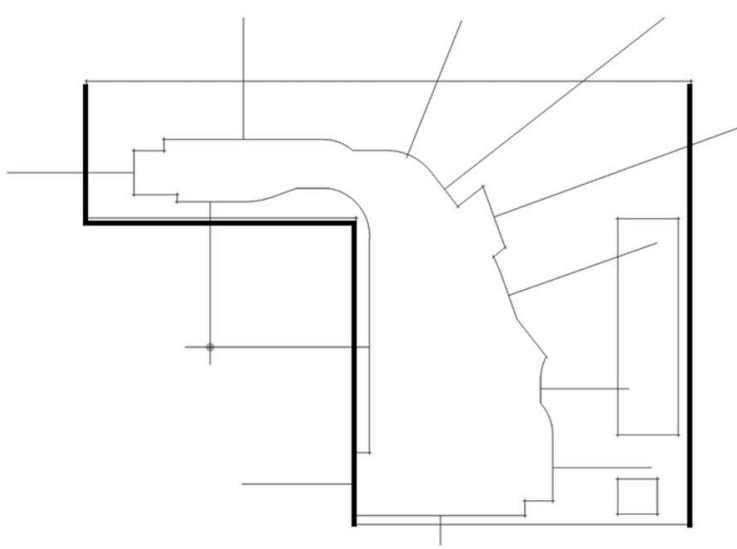

Figura 05

Museu de Arte Nacional do século XX, Roma. Zaha Hadid. Perímetro Envolvente.

Fonte: Vieira, 2015, p. 182 (publicação autorizada pelo autor).

\section{Terceira via: permeabilidade}

A leitura da condição de permeabilidade espacial na arquitetura é mais difícil sem o auxílio de instrumentos gráficos adequados. A mera observação dos desenhos convencionais não permite aferir com rapidez e clareza a gradação e as características desta condição. O diagrama de permeabilidade da Figura 06, construído a partir da implantação (térreo) do conjunto, tendo como referência os limites do lote, registra os principais eixos de percursos peatonais e pontos de acesso internos e externos. O diagrama de acessibilidade (Figura 07), feito com base na planta de acesso ao edifício, mostra as gradações de acessibilidade definidas para o piso principal de acesso por meio de um recurso de diferenciação por áreas cromáticas em tons de cinza, que variam do branco (máxima acessibilidade) para o preto (mínima acessibilidade). O objetivo é o 
de identificar as situações de penetrabilidade e trespasse de percursos, e avaliar a gradação de acessibilidade das áreas de acesso (internas e externas) ao conjunto.

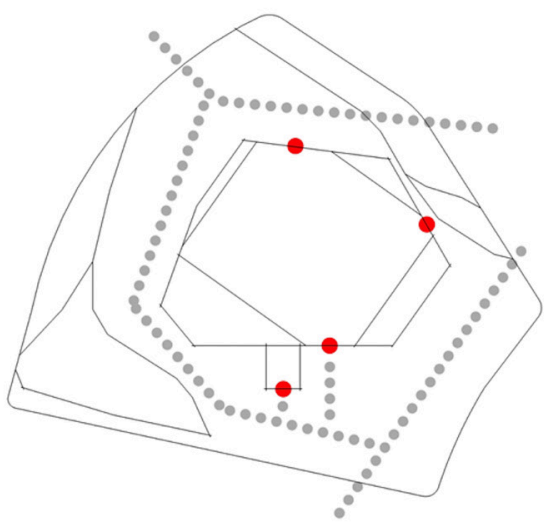

Figura 06

Casa da Música do Porto, Porto. OMA. Permeabilidade. Percursos peatonais e acessos.

Fonte: Vieira, 2015, p. 169 (publicação autorizada pelo autor).

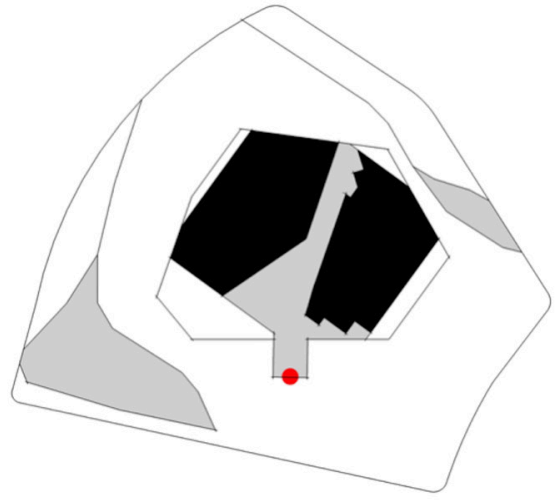

Figura 07

Casa da Música do Porto, Porto. OMA. Acessibilidade. Fonte: Vieira, 2015, p. 169 (publicação autorizada pelo autor).

\section{Quarta via: sociabilidade}

O uso de elementos gráficos para a leitura da condição espacial arquitetônica em relação à sociabilidade dos espaços visa reconhecer condições geométricas que estimulem o uso público coletivo, como por exemplo aquelas geradas pelas coberturas e ou avanços dos edifícios sobre as áreas externas de uso franco.

Para tanto, buscou-se identificar a incidência e a geometria do "espaço positivo" nas áreas externas. Do mesmo modo, interessa a incidência e a geometria dos "espaços de abrigo" externos ao edifício. O registro do "espaço positivo" (Figura 08) é construído a partir da implantação (térrea) do conjunto, tendo como referência os limites do lote. Nele são registrados os prolongamentos das linhas dos trechos de fachadas para facilitar a identificação e marcação dos "espaços positivos". O diagrama destinado à demonstração dos espaços de abrigo externo (Figura 09) foi construído a partir da implantação (térrea) do conjunto, tendo como referência os limites do lote. Nele são demarcados os espaços externos abrigados junto ao(s) edifício(s). Visa-se identificar áreas de estimulo às atividades de socialização. 


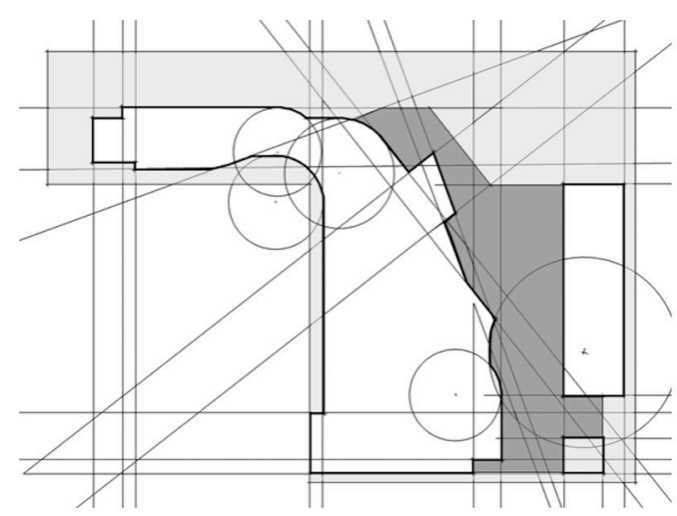

Figura 08

Museu de Arte Nacional do século XX, Roma. Zaha Hadid. Espaço positivo.

Fonte: Vieira, 2015, p. 184 (publicação autorizada pelo autor).

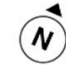

010
ESPAÇO POSITIVO

ABRIGO

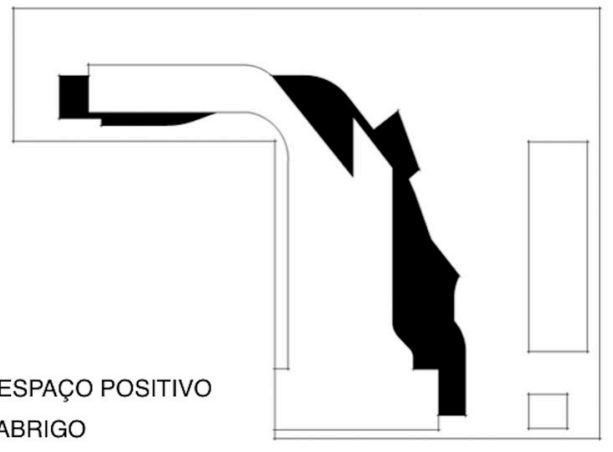

Figura 09

Museu de Arte Nacional do século XX, Roma. Zaha Hadid. Espaços de abrigo externo.

Fonte: Vieira, 2015, p. 184 (publicação autorizada pelo autor).

\section{Quinta via: fluxos}

Verificar a incidência e as características geométricas e posicionais dos espaços servidos e servidores é o que se pretende com a leitura da condição espacial arquitetônica em relação ao sistema de circulações. No diagrama que mostra a planta de setorização e fluxos do piso térreo (Figura 10) são marcados os principais eixos de circulação e distinguidas as áreas de circulação (espaços servidores) em relação aos espaços-uso (espaços servidos). O calculo de suas áreas e a anotação de suas proporções possibilita um estudo comparativo. O segundo diagrama (Figura 11) apresenta as mesmas informações que o anterior tomadas dos pisos superiores.

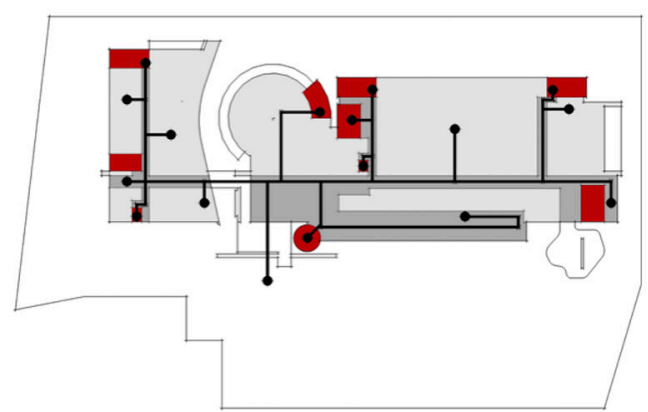

Figura 10

Museu de Arte Contemporânea de Barcelona, Barcelona. Richard Meier. Setorização e fluxos do piso térreo.

Fonte: Vieira, 2015, p. 208 (publicação autorizada pelo autor).

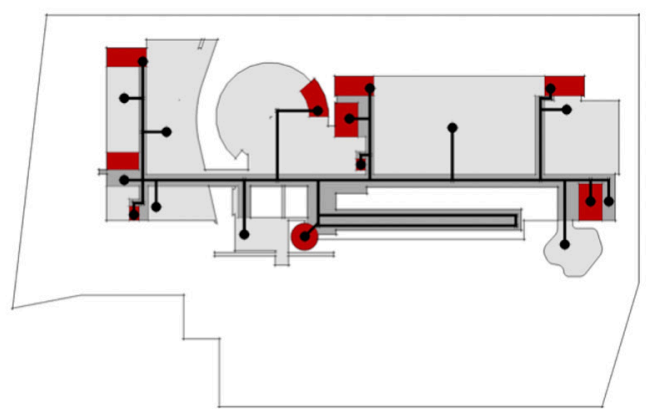

Figura 11

Museu de Arte Contemporânea de Barcelona, BarceIona. Richard Meier. Setorização e fluxos dos pisos. Fonte: Vieira, 2015, p. 208 (publicação autorizada pelo autor).

\section{Sexta via: estratificação}

Nesta "via", busca-se registrar a incidência e a geometria dos espaços verticais em um edifício, assim como 
identificar a interação espacial entre os vários estratos (camadas) do edifício. Outro objetivo é a verificação da relação geométrica entre os pisos e entre estes e a cobertura. A isométrica do conjunto e sua versão seccionada são representadas em dois diagramas (Figura 12 e 13) que, juntamente com a anotação dos espaços verticais no corte transversal (Figura 14) dão conta de registrar a verticalidade espacial arquitetônica.
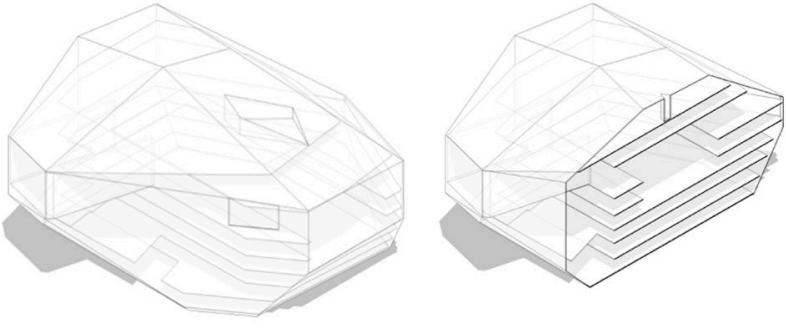

Figura 12 e 13

Casa da Música do Porto, Porto. OMA. Esq.: Isométrica do volume principal. Dir.: Isométrica seccionada.

Fonte: Vieira, 2015, p. 171 (publicação autorizada pelo autor).

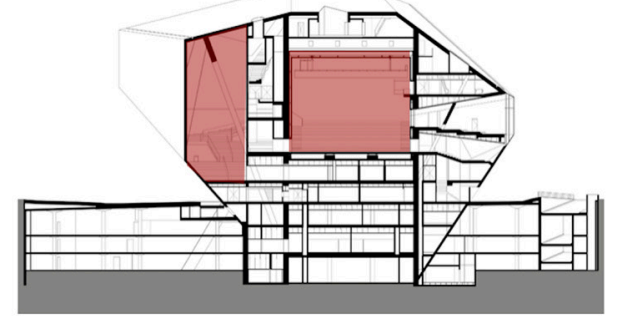

Figura 14

Casa da Música do Porto, Porto. OMA. Verticalidade espacial.

Fonte: Vieira, 2015, p. 172 (publicação autorizada pelo autor)

\section{Sétima via: estrutura}

A concepção estrutural adotada em uma obra de arquitetura corresponde à ultima "via" de leitura da condição espacial. Nela busca-se verificar a incidência e as características geométricas e posicionais dos elementos estruturais visíveis e identificar as características da estrutura de ordenação dos elementos estruturais, assim como descrever a relação de interdependência entre os elementos estruturais e a configuração dos espaços. No diagrama principal (Figura 15) apresentase a planta térrea com a marcação dos principais eixos de estrutura. As perspectivas seccionadas do conjunto (Figura 16 e 17), com a marcação dos elementos de estrutura internos, completam os diagramas.

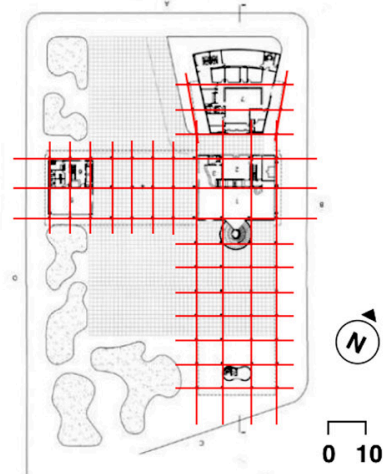

Figura 15

Ministério da Educação e Saúde do Rio de Janeiro. Lucio Costa, Oscar Niemeyer e equipe. Planta térrea com a marcação dos principais eixos de estrutura.

Fonte: Vieira, 2015, p. 159 (publicação autorizada pelo autor).

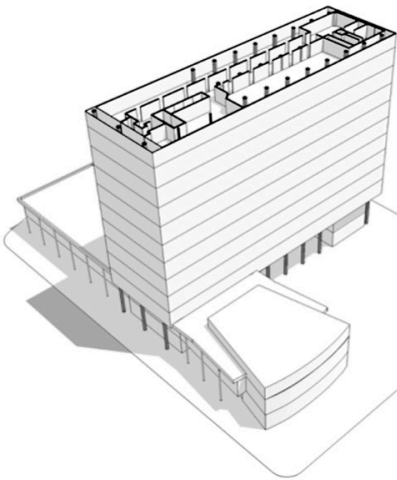

Figura 16 e 17

Ministério da Educação e Saúde do Rio de Janeiro. Lucio Costa, Oscar Niemeyer e equipe. Perspectivas seccionadas do conjunto.

Fonte: Vieira, 2015, p. 160 (publicação autorizada pelo autor). 


\section{Considerações finais}

Retomando o fio de nossa discussão, na primeira parte deste artigo traçamos um sintético histórico do desenvolvimento dos projetos de pesquisa em áreas de prática projetual desenvolvidos desde 2006, no âmbito da Faculdade de Arquitetura e Urbanismo da Universidade Presbiteriana Mackenzie e suas parcerias. Neste processo, destacam-se principalmente o estabelecimento dos indicadores de reconhecimento e análise da pesquisa acadêmica que fundamenta-se nas práticas projetuais, privilegiadamente o desenho, e redesenho, como modo de construção da argumentação fundamental de pesquisa. Os indicadores são: 1.) histórico/historiográfico e 2.) Projetual.

No presente artigo, que buscou especificamente estabelecer uma interlocução produtiva a partir da temática da mesa deste evento, buscamos examinar a tese de doutoramento de um dos autores, em busca de explicitar aspectos de como o redesenho (que se enquadra no indicador "projetual") é empregado como modo de construção de conhecimento cuja construção emerge de uma raiz histórico/historiográfica. Como esperamos ter sido possível observar, a prática do redesenho implica na construção de um olhar específico, construído com base em valores arquitetônicos cujo peso específico nos é dado pelos estudos de base histórico/historiográfica, mas cujas características só podem ser conhecidas via imagem. No caso do trabalho aqui examinado, por vias de aproximação construídas por meio do redesenho.

Um dos aspectos importantes na elaboração do método de aproximações proposto por Vieira (2015), residiu na abordagem por aproximações sucessivas, que propositadamente evocassem o processo de projeto em arquitetura. Nesse sentido, os elementos que aqui comparecem redesenhados consistem também em prática metalinguística, uma vez que consistem na construção de um discurso, ainda que imagético, sobre o processo de projeto.

No âmbito do processo de desenvolvimento da pesquisa acadêmica em áreas de prática projetual, o que encontramos no trabalho de Vieira é, em essência, uma articulação entre os indicadores projetual e histórico e historiográfico em que a própria construção da forma de "olhar o objeto" é construída intrinsecamente na articulação entre conhecimentos históricos e projetuais. Cada uma das sete vias: contexto, ocupação, permeabilidade, sociabilidade, fluxos, estratificação e estrutura reflete, em suas própria denominação, sig- 
nificados que se desdobram em duas vertentes: os significados projetuais permeados de valores construídos historicamente.

Do ponto de vista da contribuição ao debate mais amplo acerca da pesquisa acadêmica em áreas de prática projetual, este artigo procurou ainda corroborar as pesquisas e publicações que vêm reforçando a importância não apenas do reconhecimento da relevância da experiência profissional nos estudos acadêmicos sobre projeto e história da arquitetura, mas também da necessidade de se levar adiante o debate sobre os modos pelos quais a expertise profissional pode ser efetivamente convocada a serviço das interpretações histórico/historiográficas da arquitetura.

\section{Referências}

BORDEN, I.; RAY, K. R. The Dissertation: an architecture student's handbook. Architectural Press, 2009.

CROSS, N. Designerly ways of knowing: design discipline versus design science. Design Issues, Volume 17, No. 3, 2001.

CROSS, N. Designerly ways of knowing. Design Studies, 3 (4): 221-227.

FOQUÉ, R. Building Knowledge in Architecture. Asp / Vubpress / Upa, 2010.

LIMA, A. G. G.; BIGGS, M.; BÜCHLER, D. The Value of Architectural Sketches. Working Papers on Design, 4, ed. Grace Lees-Maffei. (Acesso em 04 de Junho de 2016).

LIMA, A. G. G.; BIGGS, M.; BÜCHLER, D. "Drawing about images: textual and non textual interpretation". Working Papers in Art and Design, 5, 2009. (Acesso em 04 de Junho de 2016).

LIMA, A. G. G.; ZEIN, R. V. Proyecto y Métodos proyectuales en La Investigación académica: algunos indicadores útiles. In: IV Jornadas Internacionales sobre Investigación en Arquitectura y Urbanismo, 2011, Valencia. Annales de las IV Jornadas Internacionales sobre Investigación en Arquitectura y Urbanismo. Valencia: General de Ediciones de Arquitectura, 2011.

LIMA, A. G. G.; SOUZA, C. L.; MEIRELLES, C.; CASTRO, L. G.; PISANI, M. A. J.; VILLAC, M. I.; MEDRANO, R. Proyectos, teorias e investigación: tendencias de la enseñanza en arquitectura y urbanismo. In: 100 years of teaching in architecture, 2011, Lima. Anais 100 years of teaching in architecture. Lima: Facultad de Arquitectura, Urbanismo y Artes - Universidad Nacional de Ingenieria, 2011.

LIMA, A. G. G.; BIGGS, M.; BÜCHLER, D.; PERRONE, R. A. C.; ZEIN, R. V. ; SANTOS, C.; VILLAC, M. I. BASTOS, M. A. Indicadores de Pesquisa Acadêmica em Áreas de Prática Projetual. In: V Projetar Processos de Projeto: Teorias e Práticas, 2011, Belo Horizonte. Anais do Congresso Projetar: Processos de Projeto:Teorias e Práticas. Belo Horizonte: Escola de Arquitetura da UFMG; NPGAU, 2011. V. 1. 
LAWSON, B. Como Arquitetos e Designers pensam. São Paulo: Oficina dos textos, 2011.

LIMA, A. G. G.; PERRONE, R. A. C.; ZEIN, R. V.; SANTOS, C. R. dos; FAVARO, H. A.; BIGGS, M.; VIEIRA, J. L.; JÚNIOR, M. A. C. Práticas Projetuais: práticas de projeto de arquitetas, arquitetos e designers: análise dos instrumentos de prática projetual e possíveis empregos, de forma direta ou não - na pesquisa acadêmica stricto sensu. Disponível em: $<$ https://praticasprojetuais.wordpress.com/>.

MONTANER, J. M. As formas do século XX. Barcelona: Gustavo Gili, 2002.

NORBERG-SCHULZ, C. Existencia, Espacio y Arquitectura, Barcelona: Blume, 1975.

PERRONE, R. A. C.; LIMA, A. G. G; FLÓRIO, W. (2006) The sketches and the design process in architecture. Working Papers in Art and Design 4, 2006. (Acesso em 04 de Junho de 2016).

SCRIVENER, S. Reflection in and on action and practice in creative-production doctoral projects in art and design. Working Papers in Art and Design 1, 2000. (Acesso em 30 de Maio de 2016).

WAISMAN, M. El Interior de la Historia: Historiografia Arquitectonica para Uso de Latinoamericanos. Bogotá: Escala, 2009.

VIEIRA, J. L. Vias de aproximação para uma leitura da condição espacial na arquitetura. Tese de doutorado apresentada à Faculdade de Arquitetura e Urbanismo da Universidade de São Paulo. 2015. 